\section{EXPLORATION OF THE COMMON BILE DUCT FOR STONE}

DRAINAGE WITH T-TUBE AND CHOLANGIOGRAPHY

\author{
BY
}

\author{
MICHAEL J. SMYTH, M.Ch., F.R.C.S. \\ Surgeon, E.M.S. ; Surgeon, Hospital of St. John and \\ St. Elizabeth, N.W.8
}

(With Special Plate)

In the early days of operations for cholelithiasis the majority of surgeons were content to remove the stones and drain the gall-bladder. The operation was comparatively easy and, as operations went in those days, comparatively safe, and it was regarded as the ideal surgical treatment. Not all surgeons, however, accepted this view, and there were not wanting restless intrepid spirits who did not hesitate to remove the gall-bladder if it was obviously diseased; but even they viewed with misgivings any condition which necessitated interference with the common bile duct. Their reluctance was due not so much to the added difficulties of the operation as the fear that if an actual fatality did not result they might be left with a persistent biliary fistula. Too often had they encountered fistulae following on drainage operations of the gall-bladder, and the thought no doubt was uppermost that a fistula, almost inaccessible if not irremediable, might result. Consequently the pioneers of operations upon the common bile duct were at great pains to secure a watertight closure of the duct, and as a further precautionary measure they closed the abdomen without drainage. Complete closure was found to be a mistake, for in spite of their efforts there was leakage of bile, with fatalities due to peritonitis. This danger was averted by insertion of a drainage tube down to the suture line, and it was found that the duct healed satisfactorily. Indeed, it was soon evident that, provided the duct had not been grossly damaged, it required little suturing. Some even went so far as to omit suturing altogether, with no untoward result; in fact, the danger of fistula was more imaginary than real, and if a temporary fistula were required for hepatic drainage, then it was necessary to stitch a tube in the duct itself, the duct again closing rapidly when the tube came away.

Granted the remarkable healing powers of the common bile duct; yet it has always been a most debated step among surgeons as to whether or not exploration of the duct should be carried out in all operations for cholelithiasis. It adds to the time and gravity of the operation, since it is performed at depth-sometimes at great depth and with great difficulty. Obviously if the duct contains a stone it must be removed, for cholecystectomy will not rid the patient of his trouble: as well might one lock the stable door when the horse has bolted. It is in cases, however, in which there is little or no indication for exploration of the duct or in which the surgeon is in doubt as to whether he is dealing with an impacted stone, an enlarged gland, or a thickened portion of pancreas, that controversy arises. There are those who affirm that the duct should be explored in all cases in which operation is undertaken for cholelithiasis or cholecystitis, and they produce statistics to prove their point. Statistics, as someone has remarked, may be made to prove anything, even the truth, but much evidence is accumulating to prove the contention that this step should be more often carried out. In many instances where patients have had their gallbladders removed they have not been completely relieved of their sufferings, and indeed to their great disappointment sometimes have a return of symptoms in all intensity. This is due to stone in the common bile duct that has been overlooked or neglected. If not due to actual stone, the advocates of common bile duct exploration say it is due to biliary mud or inspissated mucus, which could have been remedied by drainage of the duct and dilatation of the sphincter of Oddi, a muscle which they maintain is always in spasm in such cases. A second operation is not welcomed by the patient or the surgeon, for it is more difficult and more dangerous.

Surgeons are well aware of the added difficulties and dangers of common bile duct exploration, but Lahey of Boston, who is a strong advocate of this step, thinks that with a surgeon of competence and experience in biliary surgery this step does not entail any more danger to the patient-in fact, quite the contrary. In a large series of cases in which he or his colleagues of the Lahey Clinic have explored the common bile duct, only one patient in whom no stones were found died following exploration. On the other hand, the mortality from secondary operations for stone in the duct was out of proportion. He further warns against too much reliance being placed upon clinical features which heretofore were regarded as a sine qua non of stone in the common bile duct. The following summary embodies most of his findings.

\section{Clinical Features of Stone in Common Bile Duct}

Jaundice-This symptom, which was considered a sheetanchor in diagnosis, is absent in at least one-third of cases. Lahey in a review of three separate series of cases in which stones were present in the common bile duct found that jaundice was absent, and never had been present, in not less than $37 \%$ of cases-in his last series $39 \%$. Snell of the Mayo Clinic lays emphasis on the fact that stones in the common bile duct rarely if ever completely occlude the duct for long, and so the stools or duodenal contents always contain bile at one time or another. On the other hand, an evanescent jaundice associated with colic and cholelithiasis does not necessarily mean a stone in the common bile duct, as it may be due to hepatitis or mild cholangitis.

Colic.-From 75 to $80 \%$ of patients suffer from upper abdominal colic at some stage of the disease. This means that at least $20 \%$ do not have acute pain, though they may suffer perhaps from indigestion, with intolerance to certain foods, such as eggs, fats, and so on. It is stated that the colic is most often referred to the right upper abdominal quadrant, but in my own experience of eight cases in which stone was found only in the common duct the pain was referred to the epigastrium and radiated through to the back between the shoulder-blades.

Chills and Fevers (Charcot's Intermittent Hepatic Fever) due to Cholangitis and Hepatitis.-In Lahey's series chills and fevers were present in only $4.2 \%$ of cases-a remarkably low figure which was attributed to the fact that a large proportion were operated upon early, and also to the practice of exploring the ducts in all biliary operations.

Duodenal Drainage.-Aspiration of the duodenal contents in Lahey's series yielded crystals of calcium or cholesterol in the drainage sediment in 30 out of 32 cases in which stones were found in the common bile duct at operation.

$X$-Ray.-Cholecystography is indirectly most helpful, but of course the dye does not outline the common duct. Sometimes if the stone in the duct contains enough calcium it may be made to show up and its position be located by the aid of barium in the duodenum.

\section{Indications for Exploration of Common Bile Duct}

At operation the following findings are suggestive of stone in the common bile duct: (1) Thickened and contracted gall-bladder. (2) Dilated cystic duct: normally the duct admits a probe with difficulty. (3) Dilated common duct (normally a quarter of an inch in diameter) which has lost its colour. Even in the presence of enormous 
dilatation, as sometimes happens in carcinoma of the head of the pancreas, the duct will retain its bluish colour, but when dilatation is associated with stone and infection it alters to a pinkish grey or yellow.

Among my own cases there were eight in which stones were found only in the common bile duct. In five of these the gall-bladder had been removed at a previous operation. All these patients suffered from intermittent colic, the pain being referred to the epigastrium with radiation between the shoulder-blades. The pain was not referred to the right hypochondrium. In one case in which the common bile duct had been explored six months previously by a competent surgeon the severity of the colic combined with rigidity of the abdominal muscles led to a diagnosis of perforated ulcer; at operation the tissues surrounding the duct were oedematous and somewhat bile-stained, and a good-sized stone was found in the duct. Six of the patients complained of jaundice, but the other two remained free from this symptom throughout their illness. The gall-bladder in each of the cases in which cholecystectomy had not been performed was unmistakably pathological-shrunken, with thickened walls and altered colour-and the cystic duct in each was widely dilated as if its passage had just been forced by a stone. The gall-bladder in one case was no bigger than the terminal digit of a mediumsized finger, and would barely have accommodated the stone which it had apparently expelled into the common duct.

At operation the ducts must be palpated carefully for stone. The index finger of the left hand is passed into the foramen of Winslow and the duct carefully examined with finger and thumb, aided by the fingers of the right hand in front. Some surgeons prefer to carry out this examination standing on the left side of the patient, reversing the position of the hands for examination. If after careful palpation the operator is still in doubt bile should be withdrawn from the duct by a hypodermic syringe. Normal bile is clear, is golden yellow in colour, and stones will not be found associated with it. On the other hand, if bile is black or cloudy or contains flocculi, stones will rarely be absent from the duct.

It is unnecessary here to give the surgical technique of exploration of the common duct in detail. I do not use a bridge to elevate the costal margin, as anaesthetists find that it causes a fall in the blood pressure. It is better to explore the common duct through a separate incision than to attempt to explore through the severed end of the cystic duct. A suction apparatus should be in use, and, in addition to the usual packs, a small gauze pack should be inserted in the foramen of Winslow to prevent leakage into the lesser sac. Not only should the common bile duct be explored, but also both hepatic ducts for stones which escape upwards. This examination is done with a scoop or a Desjardins forceps. Elusive stones can sometimes be evacuated by flooding the ducts with saline and coaxing the stone towards the opening by means of the suction-tube inserted into the duct. Bougies should be passed down the duct to ascertain if the opening into the duodenum is patent, and dilatation of the sphincter of Oddi should be gently carried out with bougies-silkweb olivary bougies for preference, though some prefer to use Lister's sounds. Bougies greater than size 12 English or 22 French should not be used, for fatalities following excessive dilatation have been recorded. It may be added that the presence of the bougie in the lower end of the duct often materially aids palpation and helps to distinguish whether the particular swelling is inside or outside the duct.

It must be acknowledged, however, that even after the most careful exploration of the common bile duct by competent surgeons stones in the duct have been missed. There is, of course, the possibility that such stones have formed in the bile ducts themselves after the gall-bladder has been removed. The generally accepted view, how- ever, is that stones are formed in the gall-bladder and pass on via the cystic duct to the common duct. Some hold opposite views and believe that stones originatethe nucleus of the stone, at any rate-in the intrahepatic ducts. The composition of gall-stones and the site of their formation, then, are not of purely academic interest.

Naunyn first advanced the theory that cholesterol stones were formed in the gall-bladder and that for their formation infection and stasis were necessary. In recent years his views have been ably supported by Sir James Walton, a surgeon of great experience. Aschoff and Bacmeister maintained that a pure cholesterol stone is formed independently of infection, but that infection is necessary for the formation of a mixed stone. Boysen held the view that in all gall-stones there was a nucleus of pigment calcium, even in the so-called pure cholesterol stone. He had found small pigment-calcium stones in wholly normal gall-bladders, but cholesterol stones in inflamed gall-bladders. Rovsing agreed with Boysen that the primary factor was the formation of bilirubin-calcium stone, not in the gall-bladder, however, but by precipitation of bilirubin calcium in liver cells.

Lahey has recently added great support to the theory that stones can be formed in the ducts. He is convinced, from an experience amounting to 2,177 patients operated upon for gall-stones, that most common and hepatic duct stones are not produced in the gall-bladder but originate primarily within the common and hepatic bile ducts. "Again and again," he states, "have we found and removed stones in the common bile duct when the cystic duct was so small that even the smallest stone of bird-shot calibre would have trouble in passing through it." Rufanov (quoted by Walters) collected 57 cases of formation of stones within the intrahepatic ducts that had been reported in the literature, and reported 5 of his own.

Flint records an interesting case of a man who had four operations for biliary colic with jaundice and at each operation a pigment stone (or stones) was found in the common duct, the gall-bladder having been removed at the first operation. At the fourth operation the spleen was twice the normal size. Splenectomy rid the patient of his trouble, and he was alive and well fifteen years afterwards.

\section{Cholangiography and T-tube Drainage}

In recent years a method of visualizing the bile ductcholangiography-has been introduced, a method which may in time solve this vexed question. An opaque solution is introduced direct into the common bile duct and a radiograph taken. Any stones in the duct show up as filling defects. This method can be utilized at the time of operation (immediate cholangiography) or the solution can be introduced later through the tube which has been used for drainage of the common bile duct (delayed cholangiography). Immediate cholangiography, which has been strongly advocated by Best, necessitates special $x$-ray arrangements in connexion with the operation table, and the surgeon must wait while the negative is being developed. A needle and 20-c.cm. syringe are used for injecting the opaque solution after the bile has been aspirated from the common bile duct. This ritual will hardly appeal to surgeons who are confident of finding stones in the common bile ducts without the aid of newfangled methods, but even the most competent operators can be safeguarded against error if they will adopt the principle of using a $\mathrm{T}$-tube for drainage on the common duct and carrying out cholangiography afterwards. The ordinary straight drainage tube used by surgeons is retained in the duct by a suture of plain catgut, as chromic gut has on occasions been found to provide a nucleus for stone formation. Plain gut dissolves in the course of 
six to ten days, when the tube comes away. This period is inadequate for drainage in cases in which there has been cholangitis and hepatitis. A T-tube can be retained until the liver function has been restored to normal, and, furthermore, after an interval of twelve days, when the tube is firmly surrounded by the healing tissues, cholangiography can be carried out. If a stone has been overlooked and is discovered on $x$-ray examination it does not necessarily mean a further operation. There are now means at our command, through the aid of the T-tube, which may help to rid the patient of the stone without operation. The T-tubes supplied by manufacturers are invariably out of proportion, the cross-piece of the $T$ being longer than the common and hepatic ducts combined. The whole circumference of the cross-limb is unnecessary,

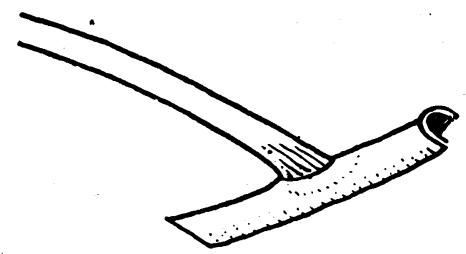

FIG. A.-T-tube prepared ready for use.

half the circumference being quite sufficient. This part of the tube should be whittled down until it measures no more than $1 \frac{1}{2}$ inches in length at the outside and half the circumference of the tube removed, for all that is required is a projecting shoulder on each side of the main stem to retain the tube in position (Fig. A). When prepared

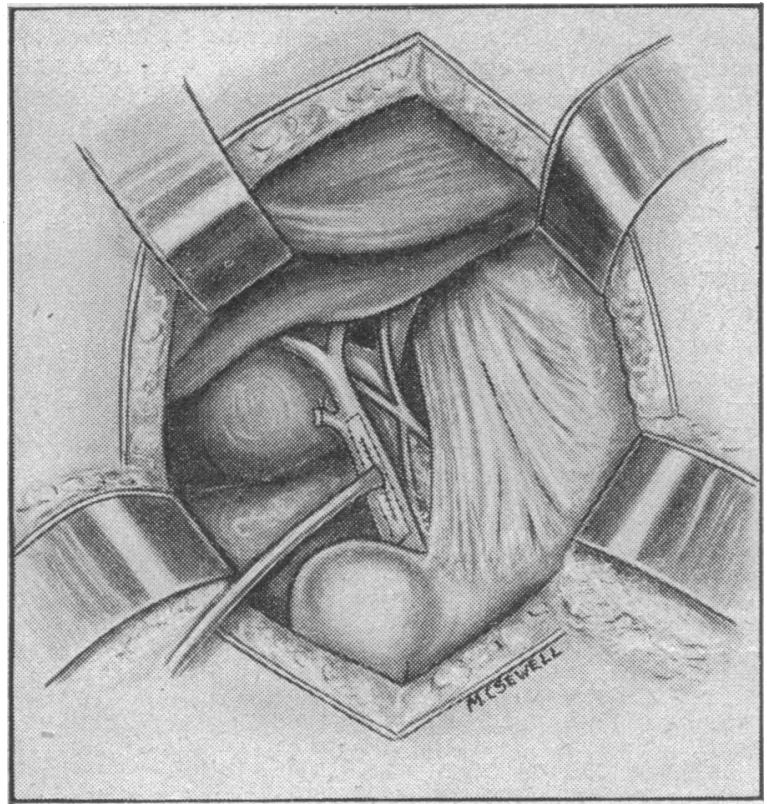

FIG. B.-Showing T-tube in position in the common bile duct.

in this way the tube is easy to introduce and is readily removed without causing the patient discomfort. The opening in the common bile duct is closed snugly around the tube and no stitch through the tube is necessary (Fig. B). An excellent type of tube is that used by Maingot, but, failing such, the operator can fashion one as described.

It is not expected, of course, that the T-tube should act as a drain for the operation area; this is provided for by a second tube which reaches down to the common duct and which for preference is brought out through a separate stab wound as recommended by Rendle Short.
The opaque solutions or contrast media most favoured have been thorotrast and lipiodol. I have already in this journal pointed out the objections to the use of these solutions. Thorotrast may be dangerous on account of its radio-active properties, and lipiodol, being thick and oily, does not mix well with bile and so filling defects may be mistaken for stones. I have tried uroselectan, but it is too apt to cause pain. Perabrodil I found quite satisfactory (see radiographs reproduced in Plate). To get the full opaque effect of the solution bile must first be aspirated from the common bile duct through the T-tube. The solution is first warmed to $100^{\circ} \mathrm{F}$., then introduced from a sterile syringe. The usual amount introduced varies from 10 to $20 \mathrm{c.cm}$., about $15 \mathrm{c.cm}$. being the average, but in some cases in which the ducts were more than usually dilated-cases of cholangiectasis and hydrohepatosis-I have used as much as $35 \mathrm{c.cm}$. The injection is stopped as soon as the patient complains of discomfort in the epigastrium, and a radiograph is taken.

If stones are discovered by cholangiography the following methods of dealing with them are tried before a second resort to operation. Bile is first aspirated, then 1 to 2 c.cm. of ether is introduced and the tube is left open so that the ether, which readily vaporizes at body temperature, may not cause too much pressure within the duct. It is hoped by this means to dissolve the stone. Treatment can be repeated several times daily. Pribram, who has tried this method extensively, claims much success for it (stones dissolved in 38 cases). Walters and Wesson advise the addition of alcohol to dilute the ether, as well as the administration of amyl nitrite to produce dilatation of the sphincter of Oddi. In this way they were successful in fragmenting a stone which had been impacted in the ampulla of Vater and securing its passage into the duodenum.

By means of opaque media it is possible to study the effects of different drugs on the sphincter of Oddi. Amyl nitrite and nitroglycerin produce the greatest dilatation. Magnesium sulphate and fats, cream, olive oil, etc., also dilate the sphincter, but atropine is uncertain. Morphine, codeine, and dilaudid, contrary to what might be expected, produce spasm of the sphincter. Walters and others at the Mayo Clinic studied particularly the effect of morphine in 9 cases of biliary colic after the gall-bladder had been removed, and found that $1 / 6$ grain of morphine sulphate produced pain, which was completely relieved by $1 / 100$ grain of glyceryl trinitrate or by inhalation of amyl nitrite. Spasm of the sphincter of Oddi is probably the cause of clay-coloured stones observed in some cases after the administration of morphine. Best of Omaha, who had not had much success with the ether method, put these findings, to good account in a number of cases. He combined the use of nitroglycerin, atropine, magnesium sulphate, and olive oil by mouth with the introduction of warm olive oil into the common bile duct through the T-tube.

I have tried the ether method without success, but in one case continued treatment on the lines laid down by Best, and was eventually successful in ridding the patient of her symptoms. The following is a brief history of the case.

A female patient, previously operated upon by another surgeon, when the gall-bladder, which contained stones, was removed; common bile duct not explored. Three months later recurring colic. Second operation (by me)-three stones removed; thought that another stone could be felt in the right hepatic duct further up, but all search proved unavailing. Bougies passed through ampulla into duodenum, and sphincter of Oddi dilated. T-tube inserted. Radiograph twelve days later: filling defect ampulla of Vater. Ether method tried unsuccessfully. Patient unfortunately had to be 
evacuated from hospital and the T-tube was removed. While awaiting admission to another hospital she continued on treatment with nitroglycerin, atropine, magnesium sulphate, and olive oil. A few days before she was due to be readmitted to hospital she sustained severe colic follow'ed by slight jaundice. and since then-now more than a year ago-has had no further trouble. I have no doubt that her attack signalized the passage of her stone into the duodenum.

\section{How Long to Retain the T-tube}

The question arises how long the T-tube should be retained in the common duct. One reads of cases, in America, in which it has been retained for periods varying from three months to a year. The time to temove the tube is when the concentration of bile salts in the bile has returned to normal. Following operation, whatever the condition of the liver, the concentration of bile salts falls for the first five days, a fall that is more pronounced if chloroform is the anaesthetic employed. The best anaesthetic would seem to be gas, oxygen, and cyclopropane. Febrile reaction following operation delays the return to normal. Unless the liver has been severely damaged by inflammation and back-pressure, the concentration of bile salts reaches normal about the fifteenth day, after which time it is safe to-remove the tube. On the other hand, in cases in which there has been prolonged continuous or intermittent jaundice, particularly if associated with fevers and chills, it will be found that the concentration of salts will be delayed, and the tube may have to be retained for a much longer period as above mentioned.

I must offer a word of warning here against too prolonged and continuous drainage. In the case above recorded there was partial obstruction to the flow of bile into the duodenum. The tube was left to drain continuously, with the result that practically all the bile escaped externally; the patient at one stage showed rapid deterioration, and it was only by the use of intravenous saline and glucose and the administration of bile salts (veracolate) by mouth that we were successful in restoring her condition. Where there is not complete obstruction the tube should be closed at intervals to allow the bile salts to escape into the duodenum. If there is complete obstruction and the bile drains only externally, it is necessary to administer bile salts by the mouth and keep the patient as well as possible by other means until such time as a short-circuit or other operation can be done to divert the bile internally.

\section{Jaundiced Cases}

A certain proportion of surgeons have always been chary about operating upon jaundiced patients, because of the danger of haemorrhage-not vigorous haemorrhage from any particular arteries, but a continuous steady ooze from the tissues which is apt to continue after operation in such cases. This lack of clotting power is due to prothrombin deficiency and can be corrected by giving vitamin $\mathrm{K}$ in combination with bile salts by mouth before operation, the bile salts being necessary for the absorption of the vitamin from the intestine. Vitamin: $K$ for oral administration is supplied under the trade name of clotogen (Abbott). Another preparation-kapilon (Glaxo) -can be given by intramuscular injection. Ainerican writers, Whipple and Rhoads particularly, speak enthusiastically of this treatment, which can be enhanced by a blood transfusion before operation.

I believe that the danger of haemorrhage in jaundiced cases has been very much exaggerated-so much so, in fact, that in the minds of many newly qualified men there exists an almost superstitious awe of the consequences of surgical intervention. Personally $I$ have never seen a case of jaundice in which a fatal ending could be attributed solely to haemorrhage following operation. No doubt such cases do occur, but some of them must be due to gross neglect of haemostasis. What does contribute more than anything else to a fatal ending in these cases is lack of adequate preliminary treatment and perhaps the efforts of the surgeon to attempt too much at operation. There is no necessity, for instance, to remove the gallbladder when the patient is very ill and the urgent need is for relief of obstruction to the common duct. The gallbladder can be left for another day. Where possible the patient should be put on a diet consisting of $75 \%$ carbohydrate, 20 to $25 \%$ protein, and not more than $5 \%$ fat for seven to fourteen days before operation. In cases of emergency, or if the patient is nauseated or vomiting, intravenous saline with glucose 5 or $10 \%$ should be given by the drip method, combined with blood transfusions. For further details of treatment I cannot do better than refer the reader to Flint's (1937) excellent paper.

\section{Summary}

Stone in the common bile duct is more often overlooked at operation than is generally realized.

Indications for exploration of the common duct for stone have been outlined-clinical features as well as conditions at operation.

Too much reliance must not be placed on the presence or absence of jaundice as a symptom. At a conservative estimate jaundice has been found to be absent in no less than one-third of the cases of stone in the common bile duct.

The use of a T-tube for drainage is strongly advocated, as it can be retained longer than the ordinary straight tube and so allows the liver a better chance of recovering to normal.

By means of the T-tube, (a) concentration of bile salts in the bile can be ascertained and an estimate be formed of liver function; (b) cholangiography can be carried out and any stones which have been overlooked detected; $(c)$ treatment can be instituted to rid the patient of such stone without resort to further operation.

I wish to acknowledge my indebtedness to $\operatorname{Dr}$. $R$. O'Donoghue and Dr. G. T. Loughborough for their kindness and help with the $x$-ray investigations.

\section{BiBLIOGRAPHY}

Baker, Hillier L, and Bacon, Chas. M. (1937). Surg. Gynec. Obstet., 65, 220. Best, R. R. (1938a). Ibid (Internat Abstr. Surg.), 66, 126.

Best, R. R. (1938a). Ibid (Inter and Hicken. N. F. (1937). Ibid., 65, 217.

Doubilet, Henry (1937). Amer. J. Roentgen., 38, 863.

Ehnmark, Ernst (1939). Acta chir. scand., Supp\}.. 82, 57.

Flint, E. R. (1937). British Medical Journat 2. 253.

Gray, Howard K. McGowan, J. M., Nettrour. W. S., and Bollman, J. L. (1937). Collected Papers of the Mavo Clin., 29, 80

Lahey, F. H. (1938). Amer. J. Surg., 40, 209

and Swinton, Neil (1935). New Engl. j. Med., 213, 1275

McGowan, J. M., Knepper, P. A., Walters, W., and Snell, A. M. (1938). Surg. Gynec. Obstet., 66, 979.

Maingot, Rodney (1936). Postgraduate Surgery vol 1, London.

Mirizzi, P. L. (1938). Lancet, 2, 366.

Rhoads, Jonathan E. (1940). Ann. Surg., 112, 568.

Short, A. Rendle (1938). Medical Annual, p. 185, Bristol.

Smyth, Michael J. (1940). British Medical Journal, 1, 504

Thorakson, P. H. T., and McMillan. J. C (1934). Canad, med. Ass. J., 31, 265.

Walters, Waltman (1938). Collected Papers of the Mayo Clin., 30, 61.

- and Wesson, H. R. (1937). Ibid., 29, 53.

Walton, Sir James (1937). Surg. Gynec. Obstet., 64, 257

Whipple, Allen O. (1940). Ann. Surg., 112, 481

The Bath Medical Book Society held its hundredth annual meeting on December 13, 1940. The society was founded for the purpose of circulating some of the reently published medical books; each member keeps a book a fortnight and passes it on to the next name on a list arranged so far as possible according to residence. The number of members is limited to twenty-five, and new members are chosen by ballot as vacancies arise. This small society fulfils a useful purpose in the medical life of Bath. Mr. A. Leonard Fuller has served as its honorary secretary for thirty-six years. 
MICHAEL J. SMYTH : EXPLORATION OF THE COMMON BILE DUCT FOR STONE

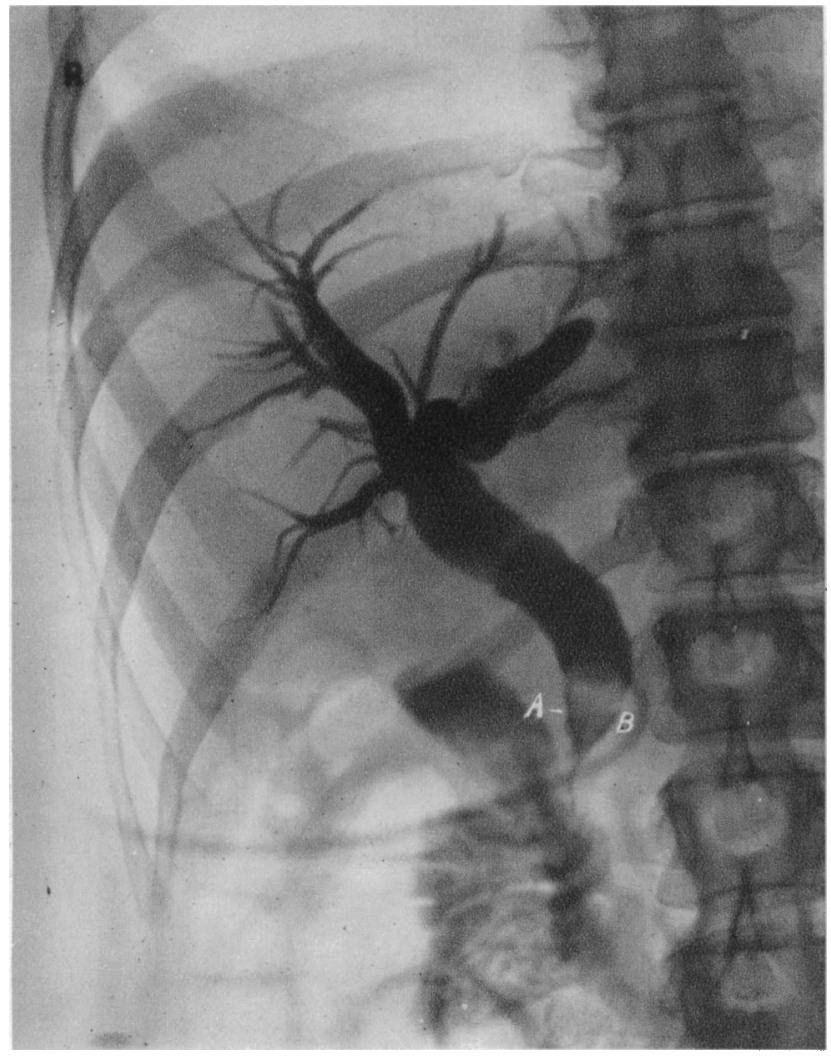

Fic. 1.-Filling defect A-B, lower end of common bile duct. Obstruction incomplete, as opaque medium (per-abrodil) is in duodenum.

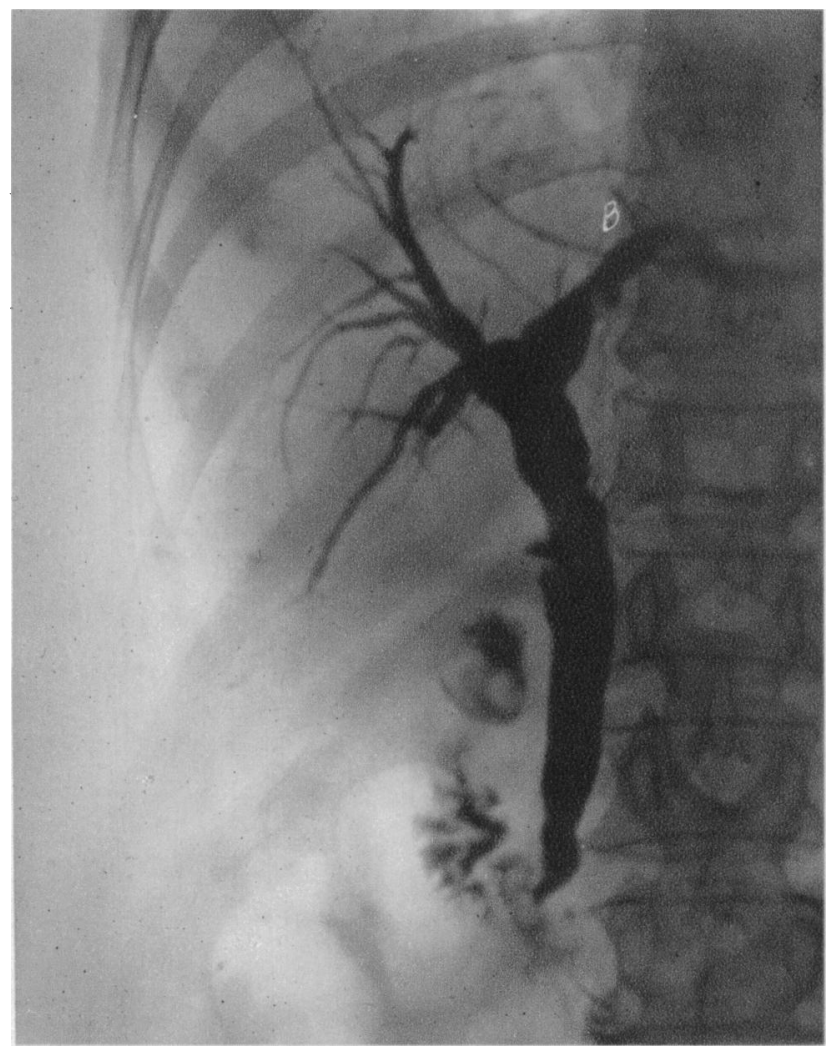

Fia. 3.-Ducts filled with uroselectan after removal of stones from common bile duct.

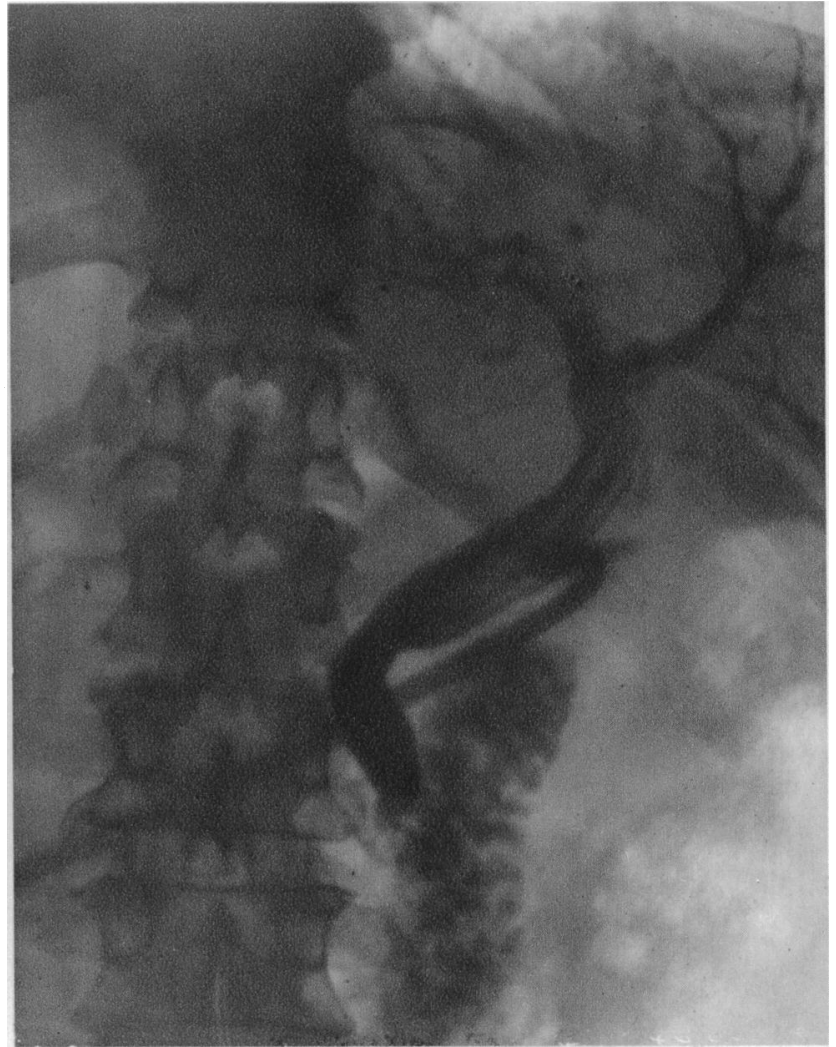

FiG. 2.-Per-abrodil in duodenum and common blle duct after removal of tive stones and dilatation of sphincter of OddI. T-tube in common blle duct also shown.

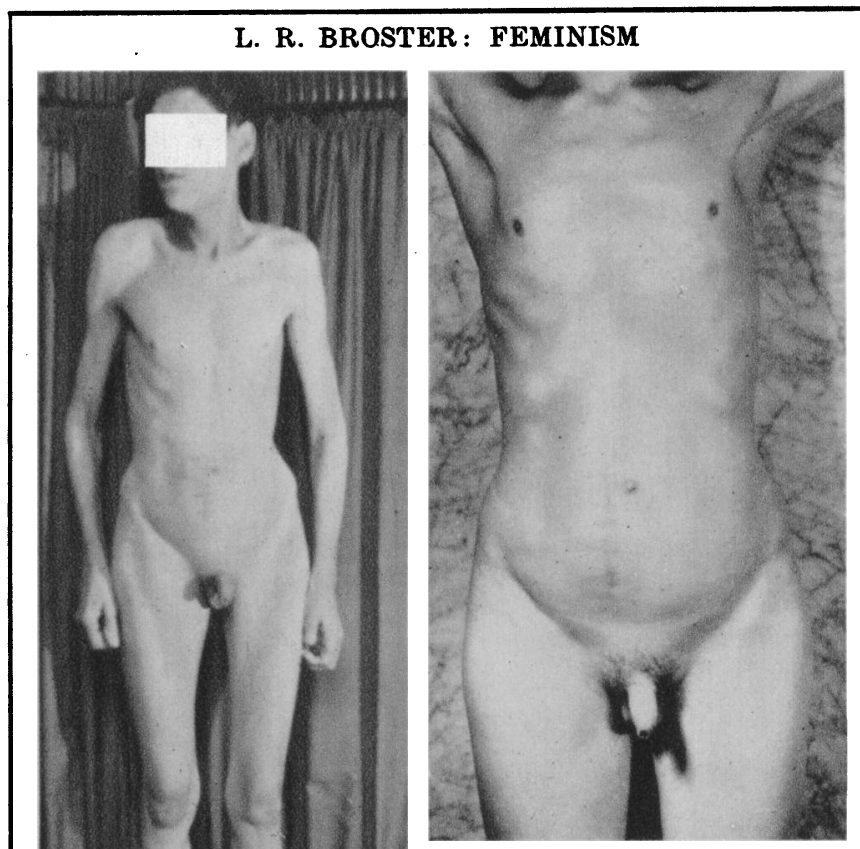

Fia. 2.--Eight months after operation. 
J. V. CUSSEN : DIRECT DRAINAGE OF LUNG CAVITIES IN PUIMONARY TUBERCULOSIS

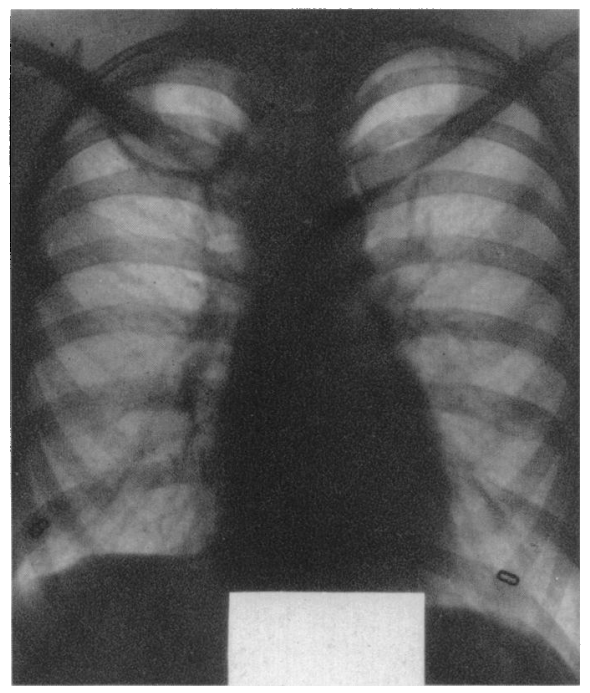

Fia. 1.-Case 1. Before operatlon. Cavity right apex.

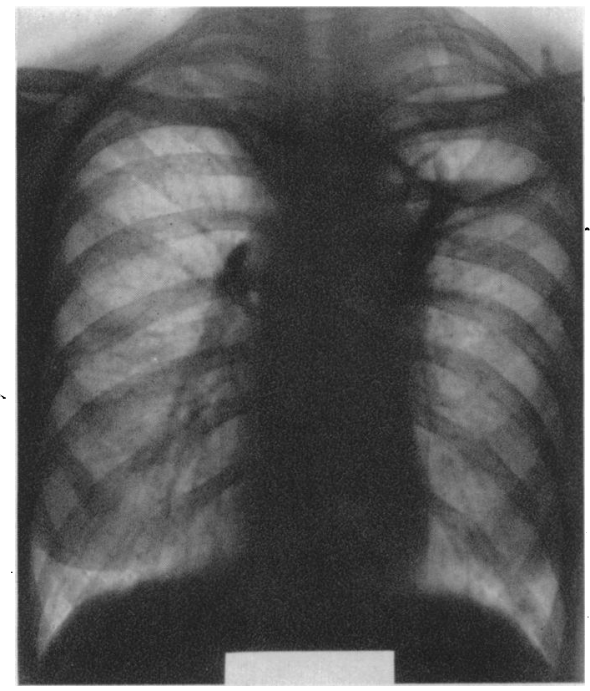

Fic. 3.-Case 2. Before operation. Cavity lef upper lobe.

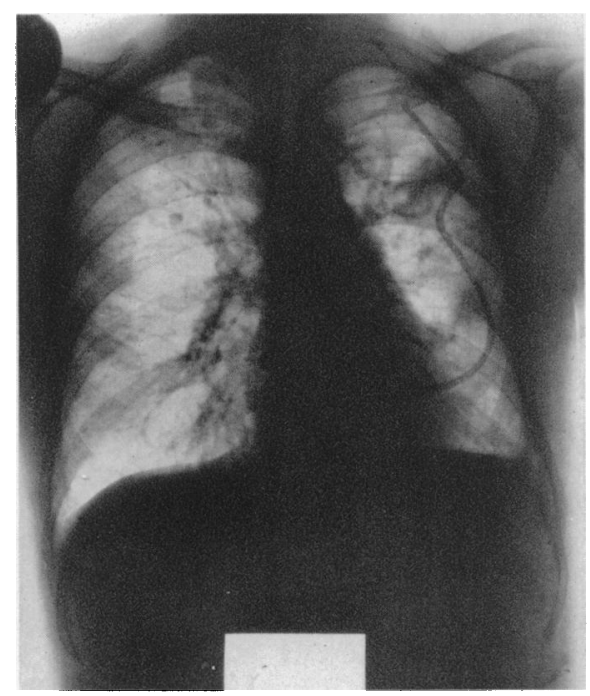

FiG. 5.-Case 8. Cavity left aper eight days after drainage.

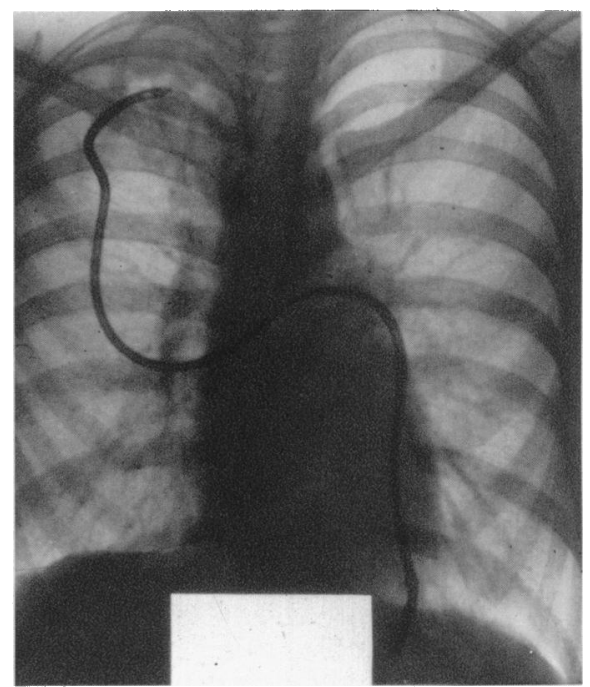

Fia. 2.-Case 1. Showing result of drainage.

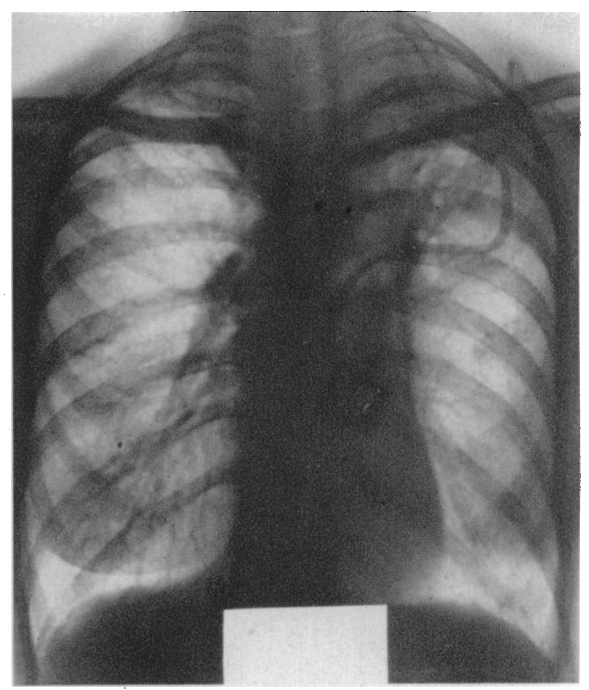

Fit. 4.-Case 2. Showing result of drainage.

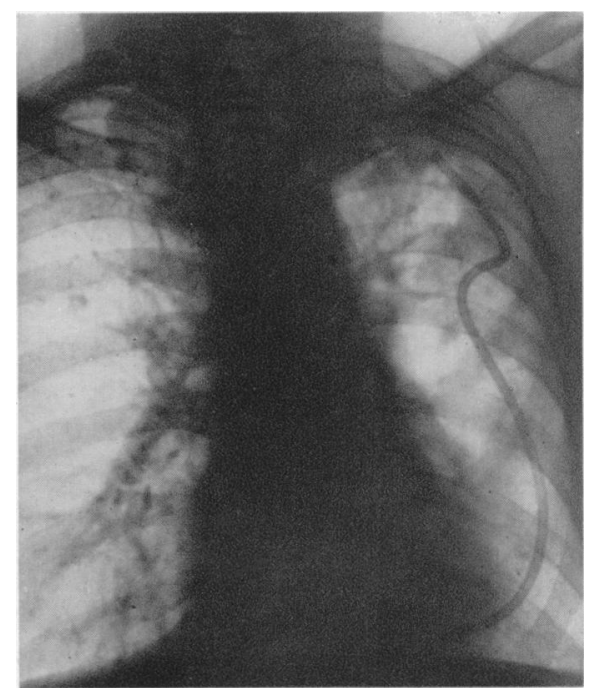

FiG. 6.-Case 3. Cavity thirteen weeks after 